\title{
Tropical Sprue (TS); Experience in a Tertiary Care Hospital
}

\author{
I PERVEEN ${ }^{\mathrm{A}}$, M HASAN ${ }^{\mathrm{B}}$, GM KIBRIA ${ }^{\mathrm{C}}$, MM RAHMAN ${ }^{\mathrm{D}}$
}

\begin{abstract}
Summary:
Background: Tropical sprue (TS) is a common cause of malabsorption in the tropics. No report has yet been published on TS in Bangladesh. This report aimed to describe clinical picture of TS patients in a tertiary care hospital.
\end{abstract}

Methods : The data were collected from the admission and discharge registers and register of follow-up clinic of Department of Gastroenterology, Bangabandhu Sheikh Mujib Medical University during the period of 1981- 2004.

Results: A total of 23 patients with a mean age of 36.42 years were diagnosed to have TS (8 females and 15 males). Mean duration of their symptoms was eight months. Important presenting features were loose motions (82.6\%) and progressive weight loss (73.91. Approximately $43.47 \%$ patients presented with abdominal discomfort or pain, $26.02 \%$ with fever and $26.03 \%$ with skin changes. Mean hemoglobin and serum albumin levels were $9.71 \mathrm{gm} / \mathrm{dl}$ and $31.16 \mathrm{gm} / \mathrm{dl}$ respectively. Fecal fat was positive in only eight cases. Contrast $X$-ray showed dilatation of small intestinal

\section{Introduction:}

Idiopathic chronic malabsorption in the tropics commonly referred to as 'Tropical sprue'; have been recognized for at least 250 years ${ }^{1}$. The condition continues to be surrounded by epidemiologic, clinical, and aetiogenetic controversies ${ }^{2}$. Hillary ${ }^{3}$, has been credited with the first description of the disease and

a. Dr. Irin Perveen, Consultant Gastrenterology,BIHS Hospital, Darus Salam, Mirpur, Dhaka.

b. Prof. Mahmud Hasan, FCPS(BD), FCPS (Pak), FRCP(Edin), FRCP(London), PhD, Ex Prof and Head. Department of Gastroenterology, BSMMU.

c. Dr. GM Kibria, FCPS, MD, Dhaka Medical College.

d. Dr. MM Rahman, FCPS, MD, Sohrwardi Medical College, Dhaka.

Address of Correspondence: Irin Perveen, Consultant Gastrenterology,BIHS Hospital, Darus Salam, Mirpur, Dhaka , Bangladesh. Email: irinperveen@yahoo.com

Received: 18 November, 2009

Accepted: 19 September, 2010 loops in four cases and flocculation of dye in two cases. Duodenal biopsy showed partial (16cases) or subtotal (four cases) villous atrophy with chronic inflammatory cell infiltrate in lamina propria in $91.3 \%$ cases. Patients treated with tetracycline or ciprofloxacin along with folic acid showed good initial response with improvement of bowel motions, weight gain and anemia. Only two patients presented with recurrent attacks.

In conclusion, TS is also prevalent in our country. A good number of TS patients presented with abdominal responses were pain and fever along with diarrhoea and weight loss. Small intestinal mucosal changes and treatment typical to TS.

Key Words: Tropical sprue, clinical profile

Key Message: The mal-absorptive disorder Tropical sprue is also prevalent in Bangladesh. Patients mostly presented with loose motions and progressive weight loss. A good number of TS patients' present with abdominal pain and fever along with diarrhoea and weight loss.

(J Bangladesh Coll Phys Surg 2011; 29: 16-20)

Manson ${ }^{4}$ introduced the Dutch term "sprue" derives from the word "sprouw". The syndrome is defined as "malabsorption of two or more substance in people in the tropics when other known causes have been excluded"5.

Little is known about prevalence and incidence of TS. Between 1943 and 1945, as many as 10\% of British soldiers evacuated from China-Burma- India theatre were diagnosed with tropical sprue. Since the World War II, tropical sprue has been frequently recognized as a cause of persistent diarrhoea, weight loss, and malabsorption among residents and travellers in the tropics, usually Asia and rarely Africa.

Although the aetiology of "tropical sprue" remains unknown, overwhelming evidence now exists that

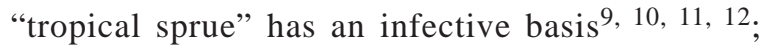
progression to the overt clinical syndrome -from an initial acute gastrointestinal infection - is probably 
under genetic control. Cook ${ }^{6}$ has proposed that intestinal infection produces nonspecific mucosal injury, which leads to the elevated plasma levels of enteroglucagon, which is responsible for slowing of intestinal transit, thereby resulting in bacterial overgrowth. The importance of fat malabsorption, with respect to the "ileal brake", slowing intestinal transit and the effect of fatty acids on colonocyte function would appear to be possible mechanism in the pathogenetic cascade.

TS is a syndrome consisting of chronic diarrhoea often with clinical features of steatorrhoea, anorexia, abdominal cramps, bloating, and prominent bowel sounds ${ }^{5,13,14}$. Lactose intolerance is common in TS and may be associated with vitamin $\mathrm{B}_{12}$ and folic acid deficiency. A subclinical or latent variant was also described.

TS in many ways remain a diagnosis of exclusion. Likely pathogens should be sought. The gold standard however is jejunal biopsy; characteristically showing thickened and blunted villi, with plasma cells, histiocytes, lymphocytes, and eosinophils in the lamina propria. If diagnostic tests are consistent with tropical sprue rapid clinical response to folic acid and an antibiotic trial is considered strong confirmatory evidence of the diagnosis.

Being a tropical country TS is considered to be an important cause of Chronic Diarrhoea in Bangladesh. However no report has yet been published on TS. This descriptive report aimed to find out the clinical profile of TS in the admitted patients during the past 20 years in a tertiary care hospital.

\section{Materials and Methods:}

This retrospective data were collected from the admission and discharge register and register of followup clinic of Department of Gastroenterology, BSMMU during the period of 1981- 2004. Diagnosis of tropical sprue based on recognition of malabsorption in patients with persistent diarrhoea after exclusion of other specific causes. Distal duodenal biopsy was done in all cases to demonstrate villous changes along with infiltration of chronic inflammatory cells in the lamina propria. If diagnostic tests were consistent with tropical sprue rapid clinical response to folic acid and an antibiotic trial was considered strong confirmatory evidence of the diagnosis.
Patients with underlying immuno-suppressive disorders, or disorders predisposing to Small intestinal bacterial overgrowth (SIBO) were excluded from the study.

Qualitatative faecal fat analysis ${ }^{15}$, haemoglobin and albumin levels were estimated in all cases to demonstrate malabsorption. Blood glucose level, thyroid function tests and HIV serology were done to exclude relevant diseases. Red cell folate and serum vitamin B12 level were estimated only in a few cases. Schilling test was once launched in INM of ex IPGMR. But the test was later abandoned. INM also failed to introduce D-xylose excretion test. For this reason dual labeled Schilling test was done in only 2 cases and D-xylose excretion test in only one case. Colonoscopy was done in more recently diagnosed cases, as the test is available now.

To exclude likely pathogens stool microscopy was done. Jejunal aspirate culture for small intestinal bacterial overgrowth and microscopic examination of duodenal contents ("touch preps" for giardiasis and other parasitic disease) were not done due to lack of feasibility. Similarly hydrogen breath test, serological test for antiendomysial or anti-tissueglutaminase antibodies and many other tests were not feasible. The patients were not on elimination diet (gluten free diet).

Barium follow-through X-ray and multiple small intestinal biopsies by endoscopy were done to exclude structural abnormality, small intestinal lymphoma, intestinal tuberculosis, immunoproliferative small intestinal disease (IPSID) and other diseases.

\section{Results:}

A total of 23 patients were diagnosed to have TS, among these $8(34.21 \%)$ were females and 15 were males. Mean age of the patients was $36.42 \pm 11.95$ years (male 36.46 yrs, female $36.37 \mathrm{yrs}$ ) with an age range of 14 to 52 years. Majority of the patients belong to third and fourth decade group.

\section{Presentation}

Mean duration of symptoms was 8 months. Loose motion was the most common presentation (82.6\%) with a mean frequency of stool 4 motions/day. Weight loss was the second most common presentation (73.9\%). Table-I describes the clinical presentation of the TS patients. A good number of patients presented with abdominal discomfort or pain (43.47\%). Skin changes (including hyperpigmentation and desquamation of skin, 
hair fall and Beau's line in the nails) were present in $26.03 \%$ cases.

\section{Table I}

Presentation of the patients with tropical sprue.

\begin{tabular}{lcccc}
\hline Symptom & Male & Female & Total & Percentage \\
\hline Loose motion & 14 & 5 & 19 & 82.6 \\
Weight loss & 10 & 7 & 17 & 73.91 \\
Pain in abdomen & 5 & 5 & 10 & 43.47 \\
Fever & 3 & 3 & 6 & 26.08 \\
Anorexia & 5 & 3 & 8 & 34.78 \\
Nausea/ vomiting & 3 & 3 & 6 & 26.08 \\
Body swelling & 4 & 1 & 5 & 21.73 \\
Skin changes & 2 & 4 & 6 & 26.08 \\
Cheilitis/glossitis & 2 & 2 & 4 & 17.39 \\
Anaenia & 6 & 7 & 13 & 56.21 \\
Oedema & 3 & 1 & 4 & 17.39 \\
hepatomegaly & 2 & 2 & 4 & 17.39 \\
\hline
\end{tabular}

\section{Laboratory data}

Mean haemoglobin level was 9.71gm/dl with a range of $4.8 \mathrm{gm} / \mathrm{dl}$ to $15.25 \mathrm{~g} / \mathrm{dl}$. A male patient presented with very low haemoglobin $(4.8 \mathrm{gm} / \mathrm{dl})$. Investigations revealed associated beta thalassaemia major. Examination of stool showed presence of ova of AL in two cases. Faecal fat ( $>60$ droplets / HPF $)^{15}$ was positive in only 8 cases (male 4 , female 4 ). Mean serum total protein (of 16 cases) was $60.64 \mathrm{gm} / \mathrm{dl}$ with a range of $43-105 \mathrm{gm} / \mathrm{dl}$ and mean serum albumin(of 17 cases) was 31.16gm/dl(range 15-42gm/dl).

\section{Imaging:}

Chest X-Ray: Revealed cardiomegaly (one male, one female) in two cases and bilateral mild pleural effusion in one case (male).

Ultrasonography:

Ascites was detected in two cases (one male, one female) and fatty change in liver was found in one case (female).
Barium study of small intestine:

Barium follow through study was done in 12 cases. Dilatation of small intestinal loops and mucosal thickening were found in 4 cases, flocculaton of dye in two cases and areas of mucosal thickening in one case.

\section{Endoscopy:}

Endoscopy was done in all cases. Duodenal ulcers were found in 3 cases, antral gastritis in one case and Bilroth type II operation was found in one case.

\section{Colonoscopy:}

Colonoscopy was done in 4 cases. All were normal.

Dual label Schilling test was done in only 2 cases and malabsorption of intestinal origin was diagnosed.

D-xylose excretion study was done in one case and the finding was normal.

Distal duodenal biopsy showed chronic inflammatory cells (lymphocytes, plasma cells, histiocytes and eosinophils) infiltrate in lamina propria in 21 cases. Subtotal villous atrophy in four (4) cases and partial villous atrophy in 16 cases. One case had only chronic inflammatory cell infiltrate without villous abnormality.

\section{Response to Therapy}

Patients were treated with folic acid along with either tetracycline or another antibiotic. All patients showed good initial response with decrease in bowel frequency, weight gain, disappearance of oedema and raise of haemoglobin level. Only four(4) patients returned for follow up one month after discharge. Physical examination and laboratory data revealed continued improvement. Two patients presented with recurrent attack with good response to therapy during each attack.

\section{Table-II}

\section{Laboratory data.}

\begin{tabular}{lccc}
\hline & Male & Female & Total $/ \%$ \\
\hline Mean Hb level & $10.76 \pm 2.57 \mathrm{gm} / \mathrm{dl}$ & $9.99 \pm 1.57 \mathrm{gm} / \mathrm{dl}$ & $9.71 \pm 2.3 \mathrm{gm} / \mathrm{dl}$ \\
MeanWBC count & $10.88 \mathrm{X} 10^{9}$ & $8.7 \mathrm{X} 10^{9}$ & $9.96 \mathrm{X} 10^{9}$ \\
Mean STP & $61.0 \pm 8.6 \mathrm{gm} / \mathrm{dl}$ & $60.14 \pm 14.91 \mathrm{gm} / \mathrm{dl}$ & $60.64 \pm 11.18 \mathrm{gm} / \mathrm{dl}$ \\
Mean serum albumin & $33.75 \pm 8.24 \mathrm{gm} / \mathrm{dl}$ & $26.71 \pm 10.84 \mathrm{gm} / \mathrm{dl}$ & $31.16 \pm 9.64 \mathrm{gm} / \mathrm{dl}$ \\
Faecal fat & 4 & 4 & $34.78 \%$ \\
\hline
\end{tabular}




\section{Discussion:}

Tropical sprue, a primary malabsorption syndrome affecting residents and visitors to several tropical regions occurs in India in epidemic and endemic form ${ }^{16}$. Epidemic tropical sprue has been best characterized in southern India but also in Burma, Bangladesh, and the Philippines, usually as a sequela to an outbreak of infectious diarrhoea ${ }^{17}$. Being a tropical country and in the regional territory of Indo-Pak subcontinent "tropical sprue" presumed to be prevalent in Bangladesh. Clinicians come across cases of tropical sprue in their daily practice. But no report has yet been published on tropical sprue in Bangladesh. This report aimed to give a description of tropical sprue in admitted patients in gastroenterology unit in Bangabandhu Sheikh Mujib Medical University, Dhaka in last 20 years.

The lower prevalence of TS (M: F = 1.9:1) in females may be related to lower access of females to health care facilities in Bangladesh. Like other previous reports ${ }^{13}$, ${ }^{14}$ patients mostly presented with loose motions (82.6\%) and progressive weight loss (73.91\%); only two presented with weight loss and anaemia without diarrhoea. In southern India, $1 \%$ of patients with endemic TS presents with nutritional deficiencies in the absence of diarrhoea ${ }^{16}$. Like other reports ${ }^{17}$ a good no of TS patients presented with abdominal pain/cramp (26.02\%) and fever (43.5\%) with loose motion. Two patients presented with cardiomegaly and pleraral effusion and another two persons with ascites. Underlying disorders of congestive heart failure and cirrhosis were excluded in these patients. These patients improved significantly following treatment with transfusion, nutritional supplements and antibiotic therapy. A patient with Billroth type II operation presented with chronic diarrhoea and weight loss 8 years after surgery. This patient also responded to usual treatment of TS.

Laboratory data revealed low mean haemoglobin $(9.71 \mathrm{gm} / \mathrm{dl})$ and albumin $(30 \mathrm{gm} / \mathrm{l})$ suggesting malabsorption in these patients. Though quantitative faecal fat estimation is not available in our country, qualitative faecal fat analysis gave positive results in only 8 cases (34.78\%) cases which may be related to low fat intake by our indigenous population ${ }^{10}$ as described in previous reports. Due to lack of facilities, culture of jejunal aspirate and other malabsorption studies could not be done in these patients. The findings of partial or subtotals villous atrophy along with infiltration of chronic inflammatory cells in lamina propria in distal duodenal biopsies (91.3\% cases) are consistent with the other studies ${ }^{5,7}$.

Like previous reports $5,8,11$ patients treated with either tetracycline or ciprofloxacin along with folic acid showed good initial response with improvement of bowel motions, weight gain and anemia. Clinical improvement of patients despite not on elimination diet (gluten free) provided strong evidence against coeliac disease. Only 4 patients returned for follow up and demonstrated continued improvement. Only two patients presented with recurrent attack with good response to treatment in each attack.

As this is a retrospective data the report has much inherent weakness. Patients were not randomly selected and the number of sample was small too. Much information is lacking, such as socio-economic status, food habit, general hygiene etc. Patients could not be appropriately investigated due lack of facility. Majority of the patients could not be followed up, as they did not return for follow up. Despite this report expected to provide preliminary information on tropical sprue in our country and likely to inspire researchers to carry out well designed studies on this subject.

\section{Conclusion:}

Present report suggests that as a cause of chronic diarrhoea and malabsorption, TS is also prevalent in our country. A good number of tropical sprue cases presents with abdominal pain and fever along with common features of loose motion, weight loss, anaemia, oedema and skin changes. Laboratory data revealed low mean hemoglobin and albumin levels and normal or increased faecal fat concentration in these patients. Villous changes along with chronic inflammatory cells infiltrate in mucosa were present in most of the cases. Al the patients showed good initial response to treatment with antibiotic and folic acid.

But much of the presentation and treatment of TS is not yet addressed in our country. The incidence and prevalence of TS in Bangladesh is also not known. Proper investigation facilities are to be available to exclude TS cases from Caeliac disease, SIBO and other common malabsorptive disorders. Further well-designed studies are needed involving a large number of random population and with appropriate investigations to find 
out accurate prevalence, incidence, presentation and treatment response of TS.

\section{Reference:}

1. Cook GC. Tropical gastroenterology. Oxford. Oxford University Press, 1980: 271.

2. Cook GC. Tropical sprue implication of Manson's concept. J Roy Coll Phys 1978; 12; 329-49.

3. Hillary W. Observation on the changes of the air and concomitant epidemical diseases in the island of Barbados. London: Hitch and Hawes,1759: 277.

4. Manson P. China. Imperial Maritime Custom II - special series no2. Medical reports for the half year ended $31^{\text {st }}$ march 1880 . $19^{\text {th }}$ issue. Shanghai: statistical department of the Inspectorate General, 1880: 33.

5. Baker SJ, Mathan VI: Tropical sprue in Southern India. In Wellcome Trust Collaborative Study 1961-1969. London. Churchill Livingstone, 1970: 453-467.

6. Cook GC. Aetiology and pathogenesis of post-infective tropical masabsorption(tropical sprue). Lancet 1984; 1: 721723.

7. Tomkins A, Booth CC. Tropical sprue. In Disorders of the Small Intestine. Oxford Blackwell Scientific Publications, 1985: 311-332.

8. French, J.M., Gaddie,R.,and Smith, N.N. Tropical sprue: a study of seven cases and their response to combined chemotherapy. Quart J Med 1956;25: 333-351.
9. Cook GC. Tropical sprue. In: Cox FEG, ed. The Wellcome illustrated history of tropical disease. London.Wellcome Trust, 1996:359-69.

10. Banwell JG, Orbach SL. Tropical sprue. Gut 1969; 10: 32833.

11. Klipstein FA, Holdeman LV, Corcino JJ, Moore WEC. Enterotoxigenic intstinal bacteria in tropical sprue. Ann Intern Med 1973;76: 632-41.

12. Tomkins AM, Drasar BA, James WPT. Bacterial colonization of jejunal mucosa in acute tropical sprue. Lancet 1975; i: 5962.

13. Baker SJ. Idiopatic small- intestinal disease in the tropics. In: Critical reviews in tropical medicine. New York. Plenum Publishing, 1982: 197-245.

14. Klipstein FA, Falaiye JM. Tropical sprue in expatriates from the tropics living in the continental United States. Medicine 1969; $48: 475$.

15. Martin H, Bluth MD, Rosemarie E, Hardin MD, Scott T M $\mathrm{D}$, Micheal $\mathrm{E}$ at el. Laboratory diagnosis of gastrointestinal and pancreatic disorders. In. Henry's clinical diagnosis and management by laboratory methods. $21^{\text {st }}$ edition. In: McPherson RA, Pincus MR, editors. Elsevier ; 2007. p. 292.

16. Mathan VI. Tropical sprue in southern India. R Soc Trop Med Hyg 1988; 82: 10-4.

17. Lim ML. A perspective on tropical sprue. Curr Gastroenterol Rep 2001; 3: 322-7. 